\title{
The Effects of Closed-Loop Medical Devices on the Autonomy and Accountability of Persons and Systems-CORRIGENDUM
}

\author{
PHILIPP KELLMEYER, THOMAS COCHRANE, OLIVER MÜLLER, \\ CHRISTINE MITCHELL, TONIO BALL, JOSEPH J. FINS, and NIKOLA BILLER-ANDORNO
}

http:/ / dx.doi.org/10.1017/S0963180116000359. Published online by Cambridge University Press, 16 September 2016

Owing to an oversight, the following acknowledgment was omitted from the article by Kellmeyer et al. in the December 2016 issue of Cambridge Quarterly of Heathcare Ethics: ${ }^{1}$

Funding: This work was supported by the BMBF grant 13GW0053D (authors P.K. and T.B.) and the DFG grant EXC 1086 BrainLink-BrainTools to the University of Freiburg, Germany (authors P.K., T.B., and O.M.).

\section{Note}

1. Kellmeyer P, Cohcrane T, Müller O, Mitchell C, Ball T, Fins JJ, Biller-Andorno N. Effects of closedloop medical devices on the autonomy and accountability of persons and systems. Cambridge Quarterly of Heathcare Ethics 2016;25(4):623-33. http:/ / dx.doi.org/10.1017/S0963180116000359. 